\title{
New Diesters Derived from Piperine: in silico Study and Evaluation of Their Antimicrobial Potential
}

\author{
Emmely O. Trindade, ${ }^{a}$ Helivaldo D. S. Souza, ${ }^{\circledR a}$ Maria Cláudia R. Brandão, ${ }^{b}$ \\ Hermes D. Neto, ${ }^{\circ}{ }^{c}$ Edeltrudes O. Lima, ${ }^{c}$ Bruno F. Lira, ${ }^{a}$ Petrônio F. de Athayde-Filho ${ }^{a}$ \\ and José M. Barbosa-Filho ${ }^{\circledR *, c}$ \\ aDepartamento de Química, Universidade Federal da Paraíba, 58051-900 João Pessoa-PB, Brazil \\ ${ }^{b}$ Instituto Federal da Paraíba, Campus Areia, 58397-000 Areia-PB, Brazil \\ ${ }^{c}$ Departamento de Ciências Farmacêuticas, Universidade Federal da Paraíba, \\ 58051-900 João Pessoa-PB, Brazil
}

\begin{abstract}
Piperine, previously extracted from black pepper (Piper nigrum L.), was used as a precursor for the synthesis of twelve new diester derivatives. The final products were obtained through the bimolecular nucleophilic substitution reaction $\left(\mathrm{S}_{\mathrm{N}} 2\right)$ of the alkyl 2-chloroacetates and the salt of piperic acid, obtained from the basic hydrolysis of piperine. The compounds were synthesized with yields of 55-84\% and characterized by infrared spectroscopy and ${ }^{1} \mathrm{H}$ and ${ }^{13} \mathrm{C}$ nuclear magnetic resonance. The evaluation of the compounds' potential as new drug candidates was done through an in silico study of ADME properties (absorption, distribution, metabolization and excretion) and evaluation of antimicrobial activity against bacterial strains (Staphylococcus aureus and Pseudomonas aeruginosa), yeasts (Candida albicans and Candida tropicalis) and filamentous fungi (Aspergillus fumigatus, Aspergillus flavus and Aspergillus niger). The in silico study showed that the compounds were good drug candidates and antimicrobial evaluation demonstrated that 9 of the 12 compounds exhibited a minimum inhibitory concentration (MIC) ranging 1024-256 $\mu \mathrm{g} \mathrm{mL}^{-1}$.
\end{abstract}

Keywords: piperine, diesters, antimicrobial activity

\section{Introduction}

The number of drug-resistant microorganisms is increasing at alarming rates. The antibiotic resistance crisis has been attributed to the overuse and misuse of these medications, as well as a lack of new drug development by the pharmaceutical industry. When considering the emergence of resistant strains, effective treatment of fungal and bacterial infections has become increasingly challenging for public health systems. ${ }^{1,2}$ Microorganisms such as bacteria and fungi have the genetic ability to acquire and transmit resistance to these drugs. ${ }^{3}$ Pathogenic agents resist antimicrobial action through mechanisms such as: reduction of the accessibility of the drug to its molecular target, decrease in cellular uptake and increase in drug efflux, resulting in a low and ineffective concentration of the drug, or even mutations that alter their molecular targets, rendering the antibiotic useless. ${ }^{4}$ Besides, toxicity

*e-mail: jbarbosa@ltf.ufpb.br and therapy costs are other factors that hinder adequate, successful and safe treatment against infectious agents. Accordingly, the research and discovery of new, safe and effective antibiotics is of utmost importance to tackle the growing threat of infections caused by multidrug resistant microorganisms. ${ }^{3,5}$

Piperine (1-piperoyl-piperidine) is a natural amide with a molecular formula of $\mathrm{C}_{17} \mathrm{H}_{19} \mathrm{NO}_{3}$. It is a versatile bioactive compound found in almost 2000 species of the genus Piper, being also the most abundant alkaloid present in black pepper (Piper nigrum) and long pepper (P. longum). ${ }^{6,7}$ Piperine alone has a broad spectrum of biological activities such as antiinflammatory, analgesic, anticonvulsant, antimicrobial, antioxidant, antitumor, antidepressant, hepatoprotective, antithyroid and immunomodulatory, among others. ${ }^{89}$ Its abundance in plant material, as well as its ease of extraction and possible synthetic manipulations, make piperine a rich source for the discovery of numerous derived molecules with promising biological potential. The literature reports several activities of piperine derivatives, 
such as antiinflammatory, ${ }^{10}$ antimicrobial, ${ }^{11}$ antineoplasic, ${ }^{12}$ antidiabetic, ${ }^{13}$ antichagasic ${ }^{14}$ and antivitiligo, ${ }^{15}$ among others. Thus, piperine derivatives have become notorious for its promising pharmacological activities, often superior to those of piperine itself. This in turn has led to an increased interest in the research and discovery of new molecules derived from such natural compound.

Considering these aspects, twelve new diesters derived from piperine were designed, synthesized and evaluated as new drug candidates through in silico study and evaluation of in vitro antimicrobial activity.

\section{Experimental}

\section{Chemistry}

Piperine (1) was obtained by the extraction of black pepper (P. nigrum L.) with ethanol as described by $\operatorname{Ikan}^{16}$ in 1991. The other reagents and solvents were acquired from Sigma-Aldrich (São Paulo, Brazil) and used without further purification. The progress of the reactions was monitored by thin layer chromatography (TLC) on silica gel plates. The compounds were purified by recrystallization in ethanol and the structures of compounds $\mathbf{6 a - 6 1}$ were confirmed by the following: infrared spectroscopy (IR) spectra obtained with a FTIR Shimadzu spectrometer, model IR Prestige-21, with an attenuated total reflection (ATR) accessory; ${ }^{1} \mathrm{H}$ and ${ }^{13} \mathrm{C}$ nuclear magnetic resonance (NMR) spectra and two-dimensional (2D) NMR (correlation spectroscopy (COSY), heteronuclear single quantum correlation (HSQC) and heteronuclear multiple bond correlation (HMBC)) obtained with a Varian spectrometer, Mercury model (400 MHz for ${ }^{1} \mathrm{H}$ and $101 \mathrm{MHz}$ for ${ }^{13} \mathrm{C}$ ); and melting point (mp) range on a MQAPF-3 heating plate. Deuterated dimethyl sulfoxide (DMSO- $d_{6}$ ) and deuterated chloroform $\left(\mathrm{CDCl}_{3}\right)$ were used as solvents for dissolving the samples. The chemical shifts $(\delta)$ were measured in parts per million (ppm) and the coupling constants $(J)$ in hertz $(\mathrm{Hz})$.

Isolation of the amide 1-piperoyl-piperidine (piperine) (1)

In a Soxhlet apparatus, $100 \mathrm{~g}$ of black pepper and $1000 \mathrm{~mL}$ of ethanol (95\%) were added. The mixture was refluxed for approximately $8 \mathrm{~h}$. After concentrating the extract on a rotary evaporator, $100 \mathrm{~mL}$ of an alcoholic solution of $10 \% \mathrm{KOH}$ were added, and the precipitated material was then filtered out. A small amount of water was added to the alcoholic solution until the mixture became turbid. After allowing the mixture to stand for $72 \mathrm{~h}$, a yellow precipitate formed, ${ }^{16}$ and $3.5 \mathrm{~g}$ of piperine (3.5\% yield) was obtained with the following characteristics. Molecular weight (MW) $285.34 \mathrm{~g} \mathrm{~mol}^{-1}$; mp 126-128 ${ }^{\circ} \mathrm{C}$ (lit.: ${ }^{15}$ $\left.129-130^{\circ} \mathrm{C}\right)$; IR (ATR) $v / \mathrm{cm}^{-1} 3008\left(\mathrm{C}-\mathrm{H}_{\mathrm{Ar}}\right), 1631(\mathrm{C}=\mathrm{O})$, 1581-1442 $\left(\mathrm{C}=\mathrm{C}_{\mathrm{Ar}}\right), 1249(\mathrm{C}-\mathrm{O}-\mathrm{C})$; 930 oop $\left(\mathrm{C}-\mathrm{H}_{\mathrm{Ar}}\right)$; ${ }^{1} \mathrm{H} \mathrm{NMR}\left(400 \mathrm{MHz}, \mathrm{CDCl}_{3}\right) \delta 7.40$ (ddd, J 14.7, 8.9, $1.2 \mathrm{~Hz}$, $\left.1 \mathrm{H}, \mathrm{CH}_{\text {olef }}\right), 6.95\left(\mathrm{~s}, J 1.6 \mathrm{~Hz}, 1 \mathrm{H}, \mathrm{CH}_{\mathrm{Ar}}\right), 6.86(\mathrm{dd}, J 8.1$, $\left.1.7 \mathrm{~Hz}, 1 \mathrm{H}, \mathrm{CH}_{\mathrm{Ar}}\right), 6.76-6.66\left(\mathrm{~m}, 3 \mathrm{H}, \mathrm{CH}_{\text {olef }}\right.$ and $\left.\mathrm{CH}_{\mathrm{Ar}}\right), 6.41$ (d, $\left.J 14.6 \mathrm{~Hz}, 1 \mathrm{H}, \mathrm{CH}_{\text {olef }}\right), 5.94$ (s, $\left.2 \mathrm{H}, \mathrm{OCH}_{2} \mathrm{O}\right), 3.60-3.48$ (m, 4H, $\mathrm{CH}_{2 \text { cycloalk. }}$ ), 1.64 (m, 2H, H-15, $\mathrm{CH}_{\text {2cycloalk. }}$ ), 1.591.53 (m, 4H, $\left.\mathrm{CH}_{\text {2ycloalk. }}\right) ;{ }^{13} \mathrm{C}$ NMR (101 MHz, $\left.\mathrm{CDCl}_{3}\right) \delta$ $165.5,148.2,148.1,142.8,138.4,130.9,125.3,122.5$, 119.7, 108.4, 105.6, 101.3, 46.3, 26.1, 24.6.

Preparation of $(2 E, 4 E)-5-($ benzo[d][1,3]dioxol-5-yl)penta2,4-dienoic acid (piperic acid) (2)

In a $50 \mathrm{~mL}$ flask, $2.20 \mathrm{~g}(7.72 \mathrm{mmol})$ of piperine and $22 \mathrm{~mL}$ of the ethanolic solution of $20 \% \mathrm{KOH}$ were added. The reaction mixture was refluxed with stirring for $20 \mathrm{~h}$. At the end of the reaction, the mixture was filtered, and the precipitate formed was washed with ethanol and dried. The precipitate was dissolved in water and acidified with $10 \%$ $\mathrm{HCl}$ solution down to $\mathrm{pH} 3$. The yellowish precipitate formed was filtered out, washed with water, dried and recrystallized in ethanol. ${ }^{8}$ Piperic acid was obtained at $1.67 \mathrm{~g}(94.5 \%$ yield $)$ with the following characteristics. MW $218.21 \mathrm{~g} \mathrm{~mol}^{-1}$; mp 217-218 ${ }^{\circ} \mathrm{C}$ (lit.: ${ }^{17} 216-217^{\circ} \mathrm{C}$ ); IR (ATR) $v / \mathrm{cm}^{-1} 3448$ $(\mathrm{O}-\mathrm{H}), 2922\left(\mathrm{C}-\mathrm{H}_{\text {Aliph }}\right), 1676(\mathrm{C}=\mathrm{O}), 1604-1419\left(\mathrm{C}=\mathrm{C}_{\mathrm{Ar}}\right)$, $1255(\mathrm{C}-\mathrm{O}-\mathrm{C}), 927\left(\mathrm{C}-\mathrm{H}_{\mathrm{Ar}}\right)$; ${ }^{1} \mathrm{H}$ NMR $\left(400 \mathrm{MHz}, \mathrm{CDCl}_{3}\right)$ $\delta 12.20(\mathrm{~s}, 1 \mathrm{H}, \mathrm{O}-\mathrm{H}), 7.36-7.26\left(\mathrm{~m}, 1 \mathrm{H}, \mathrm{CH}_{\text {olef }}\right), 7.23(\mathrm{~s}, 1 \mathrm{H}$, $\left.\mathrm{CH}_{\mathrm{Ar}}\right), 7.03-6.89\left(\mathrm{~m}, 4 \mathrm{H}, \mathrm{CH}_{\mathrm{Ar}}\right.$ and $\left.\mathrm{CH}_{\text {Olefin }}\right), 6.05(\mathrm{~s}, 2 \mathrm{H}$, $\mathrm{O}-\mathrm{CH}_{2}-\mathrm{O}$ ), $5.93\left(\mathrm{~d}, J 15.2 \mathrm{~Hz}, 1 \mathrm{H}, \mathrm{CH}_{\mathrm{Ar}}\right) ;{ }^{13} \mathrm{C} \mathrm{NMR}$ $\left(101 \mathrm{MHz}, \mathrm{CDCl}_{3}\right) \delta 168.1,148.5,148.4,145.1,140.2$, $130.9,125.3,123.5,121.5,108.4,106.1,101.8$.

\section{Preparation of potassium piperate (3)}

An ethanolic solution of $10 \mathrm{mmol} \mathrm{KOH}$ was slowly added to a mixture of ethanol and piperic acid $(10 \mathrm{mmol})$. The reaction mixture was stirred continuously at room temperature for $1 \mathrm{~h}$. The solid obtained was filtered and dried and had a yield of $93 \%$ and the following characteristics. MW $256.30 \mathrm{~g} \mathrm{~mol}^{-1}$; IR (ATR) $\mathrm{v} / \mathrm{cm}^{-1}$ $3022\left(\mathrm{C}-\mathrm{H}_{\mathrm{Ar}}\right), 2908\left(\mathrm{C}-\mathrm{H}_{\text {Aliph }}\right), 1550(\mathrm{C}=\mathrm{O}), 1500-1448$ $\left(\mathrm{C}=\mathrm{C}_{\mathrm{Ar}}\right), 1255(\mathrm{C}-\mathrm{O})$.

General procedure for obtaining alkyl 2-chloroacetates via Fisher esterification (5a-5h)

A mixture of 2-chloroacetic acid $(20 \mathrm{mmol})$, the respective alcohol $(\mathbf{4 a}-\mathbf{4 h})(60 \mathrm{~mL})$ and concentrated 
sulfuric acid $(1 \mathrm{~mL})$ was refluxed for $6 \mathrm{~h}$. Afterwards, the excess solvent was rotary-evaporated, and the residue poured into cold water. The residue was transferred to a separation funnel containing $250 \mathrm{~mL}$ of water, and $100 \mathrm{~mL}$ of ethyl ether were then added. The organic phase was separated, washed repeatedly with $10 \%$ sodium bicarbonate until neutral $\mathrm{pH}$ and then dried with anhydrous $\mathrm{NaSO}_{4}$. Ethyl ether was rotary-evaporated, obtaining the respective esters (5a-5h).

\section{Methyl 2-chloroacetate (5a)}

MW $108.52 \mathrm{~g} \mathrm{~mol}^{-1}$; yield: 89\%; IR (ATR) $\mathrm{v} / \mathrm{cm}^{-1} 1753$ $(\mathrm{C}=\mathrm{O}), 1317,1199(\mathrm{C}-\mathrm{O}), 1172,788(\mathrm{C}-\mathrm{Cl})$; ${ }^{1} \mathrm{H}$ NMR $\left(400 \mathrm{MHz}, \mathrm{CDCl}_{3}\right) \delta 4.05$ (s, $\left.2 \mathrm{H}, \mathrm{C}_{2 \mathrm{Aliph}}\right), 3.78$ (s, 3H, $\left.\mathrm{OC}_{3 \text { Aliph }}\right) ;{ }^{13} \mathrm{CNMR}\left(101 \mathrm{MHz}, \mathrm{CDCl}_{3}\right) \delta 167.8,53.1,40.7$.

\section{Ethyl 2-chloroacetate (5b)}

MW $122.55 \mathrm{~g} \mathrm{~mol}^{-1}$; yield: 93\%; IR (ATR) $\mathrm{v} / \mathrm{cm}^{-1} 1753$ $(\mathrm{C}=\mathrm{O}), 1311,1166(\mathrm{C}-\mathrm{O}), 1266,761(\mathrm{C}-\mathrm{Cl}) ;{ }^{1} \mathrm{H}$ NMR

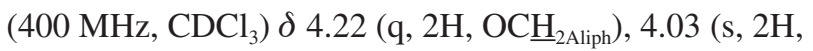
$\left.\mathrm{C}_{2 \text { Aliph }}\right), 1.27$ (t, $\left.3 \mathrm{H}, \mathrm{C}_{3 \text { Aliph }}\right) ;{ }^{13} \mathrm{C} \mathrm{NMR}\left(101 \mathrm{MHz}, \mathrm{CDCl}_{3}\right)$ $\delta$ 167.4, 62.3, 41.0, 14.1 .

\section{Propyl 2-chloroacetate (5c)}

MW $136.58 \mathrm{~g} \mathrm{~mol}^{-1}$; yield: 92\%; IR (ATR) $\mathrm{V} / \mathrm{cm}^{-1} 1755$ $(\mathrm{C}=\mathrm{O}), 1359,1184(\mathrm{C}-\mathrm{O}), 1290,788(\mathrm{C}-\mathrm{Cl}) ;{ }^{1} \mathrm{H}$ NMR

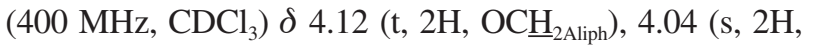
$\left.\mathrm{C}_{\text {HAliph }}\right), 1.73-1.62$ (hex, 2H, C $\left.\underline{H}_{2 \text { Aliph }}\right), 0.93$ (t, 3H, $\underline{\mathrm{H}}_{3 \text { Aliph }}$ ); ${ }^{13} \mathrm{C} \mathrm{NMR}\left(101 \mathrm{MHz}, \mathrm{CDCl}_{3}\right) \delta 167.4,67.8,41.0,21.9,10.2$.

\section{Isopropyl 2-chloroacetate (5d)}

MW $136.58 \mathrm{~g} \mathrm{~mol}^{-1}$; yield: 85\%; IR (ATR) $\mathrm{v} / \mathrm{cm}^{-1} 1751$ $(\mathrm{C}=\mathrm{O}), 1307,1103(\mathrm{C}-\mathrm{O}), 1184,840(\mathrm{C}-\mathrm{Cl}) ;{ }^{1} \mathrm{H}$ NMR $\left(400 \mathrm{MHz}, \mathrm{CDCl}_{3}\right) \delta 5.07$ (hept, $1 \mathrm{H}, \mathrm{OC}_{\text {Aliph }}$ ), 4.00 (s, $\left.2 \mathrm{H}, \mathrm{C}_{2 \text { Aliph }}\right), 1.26$ [d, $\left.6 \mathrm{H},\left(\mathrm{C}_{3 \text { Aliph }}\right)_{2}\right] ;{ }^{13} \mathrm{C}$ NMR $(101 \mathrm{MHz}$, $\left.\mathrm{CDCl}_{3}\right) \delta 166.9,70.2,41.3,21.7$.

\section{Butyl 2-chloroacetate (5e)}

MW $150.60 \mathrm{~g} \mathrm{~mol}^{-1}$; yield: 81\%; IR (ATR) $v / \mathrm{cm}^{-1} 1757$ $(\mathrm{C}=\mathrm{O}), 1309,1182(\mathrm{C}-\mathrm{O}), 1288,785(\mathrm{C}-\mathrm{Cl}) ;{ }^{1} \mathrm{H}$ NMR $\left(400 \mathrm{MHz}, \mathrm{CDCl}_{3}\right) \delta 4.17$ (t, $\left.2 \mathrm{H}, \mathrm{OC}_{2 \mathrm{Aliph}}\right), 4.04$ (s, $2 \mathrm{H}, \mathrm{C}_{2 \text { Aliph }}$ ), 1.67-1.59 (qt, 2H, $\mathrm{C}_{2 \text { Aliph }}$ ), 1.37 (sext, 2H, $\left.\mathrm{C}_{2 \text { Aliph }}\right), 0.92$ (t, $\left.3 \mathrm{H}, \mathrm{C}_{3 \text { Aliph }}\right) ;{ }^{13} \mathrm{C} \mathrm{NMR}\left(101 \mathrm{MHz}, \mathrm{CDCl}_{3}\right.$ ) $\delta$ 167.5, 66.2, 41.0, 30.5, 19.0, 13.7.

\section{Isobutyl 2-chloroacetate (5f)}

MW $150.60 \mathrm{~g} \mathrm{~mol}^{-1}$; yield: 75\%; IR (ATR) $\mathrm{v} / \mathrm{cm}^{-1} 1757$ $(\mathrm{C}=\mathrm{O}), 1311,1188(\mathrm{C}-\mathrm{O}), 1290,766(\mathrm{C}-\mathrm{Cl}) ;{ }^{1} \mathrm{H}$ NMR

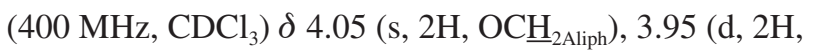
$\left.\mathrm{C}_{2 \text { Aliph }}\right), 1.96$ (hept, $\left.1 \mathrm{H}, \mathrm{C}_{\text {Aliph }}\right), 0.93$ [d, 6H, $\left.\left(\mathrm{C}_{3 \text { Aliph }}\right)_{2}\right]$; ${ }^{13} \mathrm{C} \mathrm{NMR}\left(101 \mathrm{MHz}, \mathrm{CDCl}_{3}\right) \delta 167.5,72.2,41.0,27.7,19.0$.
Pentyl 2-chloroacetate (5g)

MW $164.63 \mathrm{~g} \mathrm{~mol}^{-1}$; yield: 84\%; IR (ATR) $\mathrm{v} / \mathrm{cm}^{-1} 1753$ $(\mathrm{C}=\mathrm{O}), 1317,1199(\mathrm{C}-\mathrm{O}), 1172,788(\mathrm{C}-\mathrm{Cl}) ;{ }^{1} \mathrm{H}$ NMR

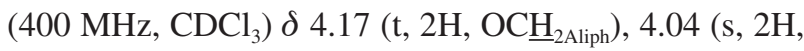
$\mathrm{C}_{2 \text { Aliph }}$ ), 1.70-1.59 (qt, $2 \mathrm{H}, \underline{\mathrm{CH}}_{2 \text { Aliph }}$ ), 1.38-1.28 (m, 4H, $\left.\mathrm{C}_{2 \text { Aliph }}\right), 0.89$ (t, 3H, $\left.\underline{\mathrm{H}}_{3 \text { Aliph }}\right) ;{ }^{13} \mathrm{C}$ NMR $\left(101 \mathrm{MHz}, \mathrm{CDCl}_{3}\right)$ $\delta$ 167.5, 66.5, 41.0, 28.2, 27.9, 22.3, 14.0.

\section{Isopentyl 2-chloroacetate (5h)}

MW $164.63 \mathrm{~g} \mathrm{~mol}^{-1}$; yield: 78\%; IR (ATR) $\mathrm{v} / \mathrm{cm}^{-1} 1757$ $(\mathrm{C}=\mathrm{O}), 1309,1184(\mathrm{C}-\mathrm{O}), 1290,758(\mathrm{C}-\mathrm{Cl}) ;{ }^{1} \mathrm{H}$ NMR $\left(400 \mathrm{MHz}, \mathrm{CDCl}_{3}\right) \delta 4.20$ (t, 2H, OC$\left.\underline{\mathrm{H}}_{2 \mathrm{Aliph}}\right), 4.03$ (s, $2 \mathrm{H}, \mathrm{C}_{2 \text { Aliph }}$ ), 1.72-1.60 (hept, $1 \mathrm{H}, \mathrm{C}_{\text {Aliph }}$ ), 1.54 (q, $2 \mathrm{H}$, $\left.\mathrm{C}_{2 \mathrm{H}}{ }_{2 \mathrm{iph}}\right), 0.91$ [d, 6H, $\left.\left(\mathrm{C}_{3 \mathrm{Aliph}}\right)_{2}\right] ;{ }^{13} \mathrm{C}$ NMR $(101 \mathrm{MHz}$, $\left.\mathrm{CDCl}_{3}\right) \delta 167.4,65.0,41.0,37.1,25.0,22.4$.

General procedure for obtaining alkyl 2-chloroacetates via acid chloride (5i-5I)

The respective alcohols $(\mathbf{4 i}-\mathbf{4 l})(10 \mathrm{mmol})$ were diluted together with triethylamine $(11 \mathrm{mmol})$, in $20 \mathrm{~mL}$ of dichloromethane at $0{ }^{\circ} \mathrm{C}$. Next, 2-chloroacetyl chloride $(11 \mathrm{mmol})$ was slowly added and the reaction mixture was vigorously stirred for $20 \mathrm{~h}$ at room temperature. Afterwards, the mixture was poured into water, washed with sodium bicarbonate and extracted with ethyl acetate. The organic phase was separated and dried with $\mathrm{Na}_{2} \mathrm{SO}_{4}$, and the solvent was removed by rotary evaporation to obtain the respective esters (5i-5l).

\section{Cyclohexyl 2-chloroacetate (5i)}

MW $176.64 \mathrm{~g} \mathrm{~mol}^{-1}$; yield: 65\%; IR (ATR) $\mathrm{v} / \mathrm{cm}^{-1}$ $1751(\mathrm{C}=\mathrm{O}), 1303,1184(\mathrm{C}-\mathrm{O}), 1288,763(\mathrm{C}-\mathrm{Cl})$; ${ }^{1} \mathrm{H}$ NMR (400 MHz, $\mathrm{CDCl}_{3}$ ) $\delta 4.84$ (qt, $1 \mathrm{H}, \mathrm{OC} \underline{\mathrm{H}}$ ), 4.02 (s, 2H, $\left.\underline{\mathrm{H}}_{2 \text { Aliph }}\right), 1.88-1.82$ (m, 2H, $\left.\underline{\mathrm{C}}_{2 \text { cycloalk. }}\right), 1.75-1.68$ (m, $\left.2 \mathrm{H}, \mathrm{C}_{2 \text { cycloalk. }}\right), 1.53-1.25$ (m, 6H, $\underline{\mathrm{C}}_{2 \text { cycloalk. }}$ ); ${ }^{13} \mathrm{C} \mathrm{NMR}$ $\left(101 \mathrm{MHz}, \mathrm{CDCl}_{3}\right) \delta 166.8,74.9,41.3,31.4,25.3,23.6$.

\section{Octyl 2-chloroacetate (5j)}

MW $206.71 \mathrm{~g} \mathrm{~mol}^{-1}$; yield: 67\%; IR (ATR) $\mathrm{v} / \mathrm{cm}^{-1} 1759$ $(\mathrm{C}=\mathrm{O})$, 1307, $1174(\mathrm{C}-\mathrm{O}), 1288,788(\mathrm{C}-\mathrm{Cl}) ;{ }^{1} \mathrm{H}$ NMR $\left(400 \mathrm{MHz}, \mathrm{CDCl}_{3}\right) \delta 4.17$ (t, $\left.2 \mathrm{H}, \mathrm{OC}_{2 \mathrm{Aliph}}\right), 4.05$ (s, $\left.2 \mathrm{H}, \underline{\mathrm{C}}_{2 \text { Aliph }}\right), 1.72-1.61$ (m, $\left.2 \mathrm{H}, \mathrm{C}_{2 \mathrm{Aliph}}\right), 1.30$ (m, 10H, $\left.\mathrm{CH}_{2 \text { Aliph }}\right), 0.87$ (t, 3H, $\left.\mathrm{CH}_{3 \text { Aliph }}\right) ;{ }^{13} \mathrm{C} \mathrm{NMR}\left(101 \mathrm{MHz}, \mathrm{CDCl}_{3}\right)$ $\delta$ 167.5, 66.5, 41.0, 31.8, 29.2, 28.5, 25.8, 22.7, 14.1 .

\section{Decyl 2-chloroacetate (5k)}

MW $234.77 \mathrm{~g} \mathrm{~mol}^{-1}$; yield: 64\%; IR (ATR) $\mathrm{V} / \mathrm{cm}^{-1} 1761$ $(\mathrm{C}=\mathrm{O}), 1307,1174(\mathrm{C}-\mathrm{O}), 1288,790(\mathrm{C}-\mathrm{Cl}) ;{ }^{1} \mathrm{H}$ NMR

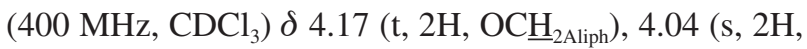
$\mathrm{C}_{2 \text { Aliph }}$ ), 1.64 (m, 2H, $\left.\underline{\mathrm{H}}_{2 \text { Aliph }}\right), 1.25$ (m, 14H, $\underline{\mathrm{CH}}_{2 \mathrm{Aliph}}$ ), 
0.85 (t, 3H, $\left.\mathrm{C}_{3 \text { Aliph }}\right) ;{ }^{13} \mathrm{C}$ NMR (101 MHz, $\left.\mathrm{CDCl}_{3}\right) \delta$ 167.5, 66.5, 41.0, 31.9, 29.6, 29.5, 29.3, 29.2, 28.5, 25.8, $22.7,14.2$.

\section{Dodecyl 2-chloroacetate (5I)}

MW $262.82 \mathrm{~g} \mathrm{~mol}^{-1}$; yield: 63\%; IR (ATR) $\mathrm{v} / \mathrm{cm}^{-1} 1761$ $(\mathrm{C}=\mathrm{O}), 1307,1172(\mathrm{C}-\mathrm{O}), 1288,790(\mathrm{C}-\mathrm{Cl}){ }^{1} \mathrm{H}$ NMR $\left(400 \mathrm{MHz}, \mathrm{CDCl}_{3}\right) \delta 4.18\left(\mathrm{t}, 2 \mathrm{H}, \mathrm{OCH}_{2 \mathrm{Aliph}}\right), 4.05$ (s, 2H, $\left.\mathrm{C}_{\text {HAliph }}\right), 1.73-1.58$ (m, 2H, $\left.\underline{\mathrm{H}}_{2 \mathrm{Aliph}}\right), 1.41-1.19$ (m, $18 \mathrm{H}$, $\left.\mathrm{C}_{2 \text { Aliph }}\right), 0.88$ (t, 3H, $\left.\underline{\mathrm{C}}_{3 \text { Aliph }}\right) ;{ }^{13} \mathrm{C}$ NMR $\left(101 \mathrm{MHz}, \mathrm{CDCl}_{3}\right)$ $\delta$ 167.5, 66.5, 41.0, 32.0, 29.7, 29.7, 29.6, 29.6, 29.4, 29.3, $28.5,25.8,22.8,14.2$.

General procedure for obtaining diesters derived from piperine (6a-6I)

In a $25 \mathrm{~mL}$ flask containing $10 \mathrm{~mL}$ of dimethylformamide (DMF), $0.002 \mathrm{~mol}$ of the respective alkyl 2-chloroacetate 5a-51 and 0.002 mol potassium iodide were added. Next, 0.022 mol potassium piperate $(3)$ was added, and the reaction mixture was heated at $100{ }^{\circ} \mathrm{C}$ with stirring for $24 \mathrm{~h}$. Afterwards, the reaction mixture was cooled, and cold distilled water was added. The precipitate formed was vacuum-filtered out, washed with water and recrystallized in ethanol.

\section{2-Methoxy-2-oxoethyl-piperate (6a)}

Yellow solid; MW $290.27 \mathrm{~g} \mathrm{~mol}^{-1}$; yield: 79\%; mp 85-86 ${ }^{\circ} \mathrm{C}$; IR (ATR) $v / \mathrm{cm}^{-1} 3074,3024\left(\mathrm{C}-\mathrm{H}_{\mathrm{Ar}}\right)$, $2943(\mathrm{C}-\mathrm{H}), 1761,1712(\mathrm{C}=\mathrm{O}), 1610,1440\left(\mathrm{C}=\mathrm{C}_{\mathrm{Ar}}\right)$, $1255(\mathrm{C}-\mathrm{O}-\mathrm{C}), 1220,1033(\mathrm{C}-\mathrm{O}), 846\left(\mathrm{C}-\mathrm{H}_{\mathrm{Ar}}\right) ;{ }^{1} \mathrm{H} \mathrm{NMR}$ $\left(400 \mathrm{MHz}\right.$, DMSO- $\left.d_{6}\right) \delta 7.45$ (ddd, $J 15.2,8.9,1.4 \mathrm{~Hz}, 1 \mathrm{H}$, H-3), 7.25 (d, 1H, J 1.6 Hz, H-7), 7.07-7.01 (m, 3H, H-4, H-5, H-11), 6.94 (d, J 8.0 Hz, 1H, H-10), 6.09 (d, J $16.3 \mathrm{~Hz}$, 3H, H-2, H-12), 4.75 (s, 2H, H-13), 3.69 (s, 3H, H-15); ${ }^{13} \mathrm{C}$ NMR (101 MHz, DMSO- $\left.d_{6}\right) \delta 168.8$ (C-14), 166.1 (C-1), 148.8 (C-9), 148.5 (C-8), 146.9 (C-3), 141.8 (C-5), 130.8 (C-6), 125.0 (C-4), 123.9 (C-11), 118.9 (C-2), 109.0 (C-10), 106.2 (C-7), 101.9 (C-12), 60.9 (C-13), 52.3 (C-15).

\section{2-Ethoxy-2-oxoethyl-piperate (6b)}

Yellow solid; MW $304.30 \mathrm{~g} \mathrm{~mol}^{-1}$; yield: 72\%; $\mathrm{mp}$ 77-78 ${ }^{\circ} \mathrm{C}$; IR (ATR) $v / \mathrm{cm}^{-1} 3080\left(\mathrm{C}-\mathrm{H}_{\mathrm{Ar}}\right), 2976$, 2893, $2787(\mathrm{C}-\mathrm{H})$, 1759, $1707(\mathrm{C}=\mathrm{O}), 1618,1442\left(\mathrm{C}=\mathrm{C}_{\mathrm{Ar}}\right)$, $1247(\mathrm{C}-\mathrm{O}-\mathrm{C}), 1134,1016(\mathrm{C}-\mathrm{O}), 856\left(\mathrm{C}-\mathrm{H}_{\mathrm{Ar}}\right) ;{ }^{1} \mathrm{H} \mathrm{NMR}$ $\left(400 \mathrm{MHz}, \mathrm{DMSO}-d_{6}\right) \delta 7.45$ (ddd, $J 15.2,8.8,1.5 \mathrm{~Hz}, 1 \mathrm{H}$, H-3), 7.25 (d, J 1.6 Hz, 1H, H-7), 7.11-7.00 (m, 3H, 3H, H-4, H-5, H-11), 6.95 (d, J 8.0 Hz, 1H, H-10), 6.09 (d, $J 15.1 \mathrm{~Hz}, 3 \mathrm{H}, \mathrm{H}-2, \mathrm{H}-12), 4.73$ (s, 2H, H-13), 4.15 (q, 2H, $\mathrm{H}-15), 1.21$ (t, 3H, H-16); ${ }^{13} \mathrm{C}$ NMR (101 MHz, DMSO- $d_{6}$ ) $\delta 168.3$ (C-14), 166.1 (C-1), 148.8 (C-9), 148.5 (C-8), 146.9
(C-3), 141.7 (C-5), 130.8 (C-6), 125.0 (C-4), 123.9 (C-11), 119.0 (C-2), 109.0 (C-10), 106.2 (C-7), 101.9 (C-12), 61.2 (C-15), 61.0 (C-13), 14.4 (C-16).

\section{2-Propoxy-2-oxoethyl-piperate (6c)}

Yellow solid; MW $318.32 \mathrm{~g} \mathrm{~mol}^{-1}$; yield: $74 \%$; $\mathrm{mp} 78-79{ }^{\circ} \mathrm{C}$; IR (ATR) $\mathrm{v} / \mathrm{cm}^{-1} 3062\left(\mathrm{C}-\mathrm{H}_{\mathrm{Ar}}\right), 2970$, $2899(\mathrm{C}-\mathrm{H}), 1745,1714(\mathrm{C}=\mathrm{O}), 1608,1448\left(\mathrm{C}=\mathrm{C}_{\mathrm{Ar}}\right)$, $1255(\mathrm{C}-\mathrm{O}-\mathrm{C}), 1211,1132,1035(\mathrm{C}-\mathrm{O}), 852\left(\mathrm{C}-\mathrm{H}_{\mathrm{Ar}}\right)$; ${ }^{1} \mathrm{H}$ NMR $\left(400 \mathrm{MHz}, \mathrm{CDCl}_{3}\right) \delta 7.49(\mathrm{dd}, J 15.2,10.8 \mathrm{~Hz}$, $1 \mathrm{H}, \mathrm{H}-3), 6.99$ (s, 1H, H-7), 6.91 (d, J $8.1 \mathrm{~Hz}, 1 \mathrm{H}, \mathrm{H}-11$ ), 6.85-6.65 (m, 3H, H-4, H-5, H-10), 6.02 (d, J $15.2 \mathrm{~Hz}$, $1 \mathrm{H}, \mathrm{H}-2), 5.98$ (s, 2H, H-12), 4.69 (s, 2H, H-13), 4.14 (t, 2H, H-15), 1.88-1.49 (m, 3H, H-16), 0.94 (t, 3H, H-17); ${ }^{13} \mathrm{C}$ NMR (101 MHz, $\left.\mathrm{CDCl}_{3}\right) \delta 168.12(\mathrm{C}-14), 166.4(\mathrm{C}-1)$, 148.8 (C-9), 148.5 (C-8), 146.4 (C-3), 141.1 (C-5), 130.8 (C-6), 124.4 (C-4), 123.2 (C-11), 118.9 (C-2), 108.6 (C-10), 106.0 (C-7), 101.5 (C-12), 66.9 (C-15), 60.8 (C-13), 22.0 (C-16), 10.3 (C-17).

\section{2-Isopropoxy-2-oxoethyl-piperate (6d)}

Yellow solid; MW $318.32 \mathrm{~g} \mathrm{~mol}^{-1}$; yield: 70\%;

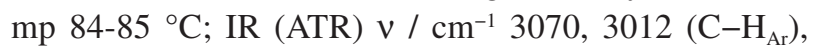
2981, $2910(\mathrm{C}-\mathrm{H}), 1737,1714(\mathrm{C}=\mathrm{O}), 1610,1450\left(\mathrm{C}=\mathrm{C}_{\mathrm{Ar}}\right)$, $1257(\mathrm{C}-\mathrm{O}-\mathrm{C}), 1217,1139,1035(\mathrm{C}-\mathrm{O}), 850\left(\mathrm{C}-\mathrm{H}_{\mathrm{Ar}}\right)$; ${ }^{1} \mathrm{H}$ NMR (400 MHz, DMSO- $d_{6}$ ) $\delta 7.45$ (ddd, $J$ 15.2, 8.6, $1.7 \mathrm{~Hz}, 1 \mathrm{H}, \mathrm{H}-3), 7.25$ (d, J $1.6 \mathrm{~Hz}, 1 \mathrm{H}, \mathrm{H}-7), 7.11-6.99$ (m, 3H, H-4, H-5, H-11), 6.94 (d, J 8.0 Hz, 1H, H-10), 6.09 (d, J $20.8 \mathrm{~Hz}, 3 \mathrm{H}, \mathrm{H}-2, \mathrm{H}-12), 5.07-4.89$ (m, 1H, H-15), 4.69 (s, 2H, H-13), 1.21 (d, 6H, H-16, H-16'); ${ }^{13} \mathrm{C}$ NMR (101 MHz, DMSO- $\left.d_{6}\right) \delta 167.8$ (C-14), 166.1 (C-1), 148.8 (C-9), 148.5 (C-8), 146.8 (C-3), 141.7 (C-5), 130.8 (C-6), 125.0 (C-4), 123.9 (C-11), 119.0 (C-2), 109.0 (C-10), 106.2 (C-7), 101.9 (C-12), 68.9 (C-15), 61.0 (C-13), 21.9 (C-16, C-16').

\section{2-Butoxy-2-oxoethyl-piperate (6e)}

Yellow solid; MW $332.35 \mathrm{~g} \mathrm{~mol}^{-1}$; yield: $84 \%$; mp 70-71 ${ }^{\circ} \mathrm{C}$; IR (ATR) $\mathrm{v} / \mathrm{cm}^{-1} 3026\left(\mathrm{C}-\mathrm{H}_{\mathrm{Ar}}\right), 2960$, $2872(\mathrm{C}-\mathrm{H}), 1745,1718(\mathrm{C}=\mathrm{O}), 1618,1444\left(\mathrm{C}=\mathrm{C}_{\mathrm{Ar}}\right), 1256$ (C-O-C), 1211, 1128, $1035(\mathrm{C}-\mathrm{O}), 848\left(\mathrm{C}-\mathrm{H}_{\mathrm{Ar}}\right) ;{ }^{1} \mathrm{H}$ NMR $\left(400 \mathrm{MHz}\right.$, DMSO- $\left.d_{6}\right) \delta 7.45$ (ddd, $J 15.2,8.6,1.8 \mathrm{~Hz}, 1 \mathrm{H}$, H-3), 7.25 (d, J 1.6 Hz, 1H, H-7), 7.10-6.98 (m, 3H, H-4, H-5, H-11), 6.94 (d, J 8.0 Hz, 1H, H-10), 6.09 (d, J $15.2 \mathrm{~Hz}$, $3 \mathrm{H}, \mathrm{H}-2, \mathrm{H}-12), 4.74$ (s, 2H, H-13), 4.11 (t, 2H, H-15), 1.64-1.46 (m, 2H, H-16), 1.33 (m, 2H, H-17), 0.89 (t, 3H, $\mathrm{H}-18) ;{ }^{13} \mathrm{C}$ NMR (101 MHz, DMSO- $\left.d_{6}\right) \delta 168.4(\mathrm{C}-14)$, 166.1 (C-1), 148.8 (C-9), 148.5 (C-8), 146.8 (C-3), 141.7 (C-5), 130.8 (C-6), 125.0 (C-4), 123.9 (C-11), 118.9 (C-2), 109.2 (C-10), 106.2 (C-7), 101.9 (C-12), 64.8 (C-15), 61.0 (C-13), 30.5 (C-16), 18.9 (C-17), 13.9 (C-18). 
2-Isobutoxy-2-oxoethyl-piperate (6f)

Yellow solid; MW $332.35 \mathrm{~g} \mathrm{~mol}^{-1}$; yield: 65\%; $\mathrm{mp} 67-68^{\circ} \mathrm{C}$; IR (ATR) v / $\mathrm{cm}^{-1} 2980\left(\mathrm{C}-\mathrm{H}_{\mathrm{Ar}}\right), 2924,2972$ $(\mathrm{C}-\mathrm{H}), 1753,1697(\mathrm{C}=\mathrm{O}), 1612,1435\left(\mathrm{C}=\mathrm{C}_{\mathrm{Ar}}\right), 1251$ (C-O-C), 1203, 1124, $1033(\mathrm{C}-\mathrm{O}), 867\left(\mathrm{C}-\mathrm{H}_{\mathrm{Ar}}\right) ;{ }^{1} \mathrm{H}$ NMR (400 MHz, DMSO- $d_{6}$ ) $\delta 7.45$ (ddd, $J 15.2,8.6,1.8 \mathrm{~Hz}, 1 \mathrm{H}$, H-3), 7.25 (d, J 1.6 Hz, 1H, H-7), 7.12-6.98 (m, 3H, H-4, H-5, H-11), 6.95 (d, J 8.0 Hz, 1H, H-10), 6.09 (d, J $16.0 \mathrm{~Hz}$, $3 \mathrm{H}, \mathrm{H}-2, \mathrm{H}-12), 4.76$ (s, 2H, H-13), 3.91 (d, 2H, H-15), 1.88 (m, 1H, H-16), 0.89 (d, 6H, H-17, H-17'); ${ }^{13} \mathrm{C}$ NMR $\left(101 \mathrm{MHz}, \mathrm{DMSO}-d_{6}\right) \delta 168.4(\mathrm{C}-14), 166.2$ (C-1), 148.8 (C-9), 148.5 (C-8), 146.9 (C-3), 141.7 (C-5), 130.8 (C-6), 125.0 (C-4), 123.9 (C-11), 118.9 (C-2), 109.0 (C-10), 106.2 (C-7), 101.9 (C-12), 70.7 (C-15), 61.0 (C-13), 27.7 (C-16), 19.1 (C-17, C-17').

\section{2-Oxo-2-(pentyloxy)ethyl-piperate (6g)}

Yellow solid; MW $346.38 \mathrm{~g} \mathrm{~mol}^{-1}$; yield: $60 \%$; mp 57-58 ${ }^{\circ} \mathrm{C}$; IR (ATR) $v / \mathrm{cm}^{-1} 3026\left(\mathrm{C}-\mathrm{H}_{\mathrm{Ar}}\right), 2953$, $2866(\mathrm{C}-\mathrm{H}), 1747,1712(\mathrm{C}=\mathrm{O}), 1612,1448\left(\mathrm{C}=\mathrm{C}_{\mathrm{Ar}}\right), 1257$ (C-O-C), 1217, 1130, $1041(\mathrm{C}-\mathrm{O}), 835\left(\mathrm{C}-\mathrm{H}_{\mathrm{Ar}}\right)$; ${ }^{1} \mathrm{H}$ NMR $\left(400 \mathrm{MHz}, \mathrm{DMSO}-d_{6}\right) \delta 7.45$ (ddd, $J 15.2,8.3,2.0 \mathrm{~Hz}, 1 \mathrm{H}$, H-3), 7.25 (d, J 1.6 Hz, 1H, H-7), 7.10-6.98 (m, 3H, H-4, H-5, H-11), 6.94 (d, J 8.0 Hz, 1H, H-10), 6.09 (d, J $15.8 \mathrm{~Hz}$, $3 \mathrm{H}, \mathrm{H}-2, \mathrm{H}-12), 4.74$ (s, 2H, H-13), 4.10 (t, 2H, H-15), 1.58 (q, 2H, H-16), 1.34-1.17 (m, 4H, H-17, H-18), 0.86 (t, 3H, $\mathrm{H}-19) ;{ }^{13} \mathrm{C}$ NMR (101 MHz, DMSO- $\left.d_{6}\right) \delta 168.4$ (C-14), 166.1 (C-1), 148.8 (C-9), 148.5 (C-8), 146.8 (C-3), 141.7 (C-5), 130.8 (C-6), 125.0 (C-4), 123.9 (C-11), 118.9 (C-2), 109.0 (C-10), 106.2 (C-7), 101.9 (C-12), 65.1 (C-15), 61.0 (C-13), 28.1 (C-16), 27.8 (C-17), 22.1 (C-18), 14.2 (C-19).

\section{2-Isopentyloxy-2-oxoethyl-piperate (6h)}

Yellow solid; MW $346.38 \mathrm{~g} \mathrm{~mol}^{-1}$; yield: 55\%; mp 83-84 ${ }^{\circ} \mathrm{C}$; IR (ATR) $v / \mathrm{cm}^{-1} 3025\left(\mathrm{C}-\mathrm{H}_{\mathrm{Ar}}\right), 2951$, $2904(\mathrm{C}-\mathrm{H}), 1753,1714(\mathrm{C}=\mathrm{O}), 1604,1446\left(\mathrm{C}=\mathrm{C}_{\mathrm{Ar}}\right), 1257$ (C-O-C), 1217, 1128, $1010(\mathrm{C}-\mathrm{O}), 835\left(\mathrm{C}-\mathrm{H}_{\mathrm{Ar}}\right) ;{ }^{1} \mathrm{H} \mathrm{NMR}$ $\left(500 \mathrm{MHz}, \mathrm{CDCl}_{3}\right) \delta 7.49(\mathrm{dd}, J 15.1,11.0 \mathrm{~Hz}, 1 \mathrm{H}, \mathrm{H}-3)$, 6.99 (s, 1H, H-7), 6.92 (d, J 7.9 Hz, 1H, H-11), 6.86-6.68 (m, 3H, H-4, H-5, H-10), 6.02 (d, J $15.3 \mathrm{~Hz}, 1 \mathrm{H}, \mathrm{H}-2$ ), 5.98 (s, 2H, H-12), 4.68 (s, 2H, H-13), 4.21 (t, 2H, H-15), 1.69 (m, 1H, H-17), 1.55 (q, 2H, H-16), 0.92 (d, 6H, H-18, $\left.\mathrm{H}-18^{\prime}\right) ;{ }^{13} \mathrm{C} \mathrm{NMR}\left(126 \mathrm{MHz}, \mathrm{CDCl}_{3}\right) \delta 168.2(\mathrm{C}-14), 166.4$ (C-1), 148.8 (C-9), 148.5 (C-8), 146.4 (C-3), 141.1 (C-5), 130.5 (C-6), 124.4 (C-4), 123.2 (C-11), 118.9 (C-2), 108.6 (C-10), 106.0 (C-7), 101.5 (C-12), 64.1 (C-15), 60.8 (C-13), 37.3 (C-16), 25.1 (C-17), 22.5 (C-18, C-18').

\section{2-Cyclohexyloxy-2-oxoethyl-piperate (6i)}

Pale yellow solid; MW $358.39 \mathrm{~g} \mathrm{~mol}^{-1}$; yield: $80 \%$; mp 112-114 ${ }^{\circ} \mathrm{C}$; IR (ATR) v / cm ${ }^{-1} 3022\left(\mathrm{C}-\mathrm{H}_{\mathrm{Ar}}\right), 2929$,
$2858(\mathrm{C}-\mathrm{H}), 1753,1716(\mathrm{C}=\mathrm{O}), 1606,1446\left(\mathrm{C}=\mathrm{C}_{\mathrm{Ar}}\right)$, $1257(\mathrm{C}-\mathrm{O}-\mathrm{C}), 1215,1132,1043(\mathrm{C}-\mathrm{O}), 806\left(\mathrm{C}-\mathrm{H}_{\mathrm{Ar}}\right)$; ${ }^{1} \mathrm{H}$ NMR (400 MHz, DMSO- $d_{6}$ ) $\delta 7.45$ (ddd, $J$ 15.2, 8.5, $1.8 \mathrm{~Hz}, 1 \mathrm{H}, \mathrm{H}-3), 7.25$ (d, J 1.6 Hz, 1H, H-7), 7.11-6.97 (m, 3H, H-4, H-5, H-11), 6.94 (d, 1H, J 8.0 Hz, H-10), 6.09 (d, 3H, J 16.1 Hz, H-2, H-12), 4.84-4.65 (m, 3H, H-15, H-13), 1.85-1.72 (m, 2H, H-16), 1.71-1.57 (m, 2H, H-16'), 1.56-1.16 (m, 6H, H-17, H-17', H-18); ${ }^{13} \mathrm{C}$ NMR (101 MHz, DMSO- $\left.d_{6}\right) \delta 167.7$ (C-14), 166.1 (C-1), 148.8 (C-9), 148.5 (C-8), 146.8 (C-3), 141.7 (C-5), 130.8 (C-6), 125.0 (C-4), 123.9 (C-11), 119.0 (C-2), 109.0 (C-10), 106.2 (C-7), 101.9 (C-12), 73.3 (C-15), 61.2 (C-13), 31.5 (C-16, C-16'), 25.2 (C-17, C-17'), 23.3 (C-18, C-18').

\section{2-Octyloxy-2-oxoethyl-piperate (6j)}

Yellow solid; MW $388.46 \mathrm{~g} \mathrm{~mol}^{-1}$; yield: $73 \%$; $\mathrm{mp}$ 69-70 ${ }^{\circ} \mathrm{C}$; IR (ATR) v / $\mathrm{cm}^{-1} 3014\left(\mathrm{C}-\mathrm{H}_{\mathrm{Ar}}\right), 2951$, 2927, $2858(\mathrm{C}-\mathrm{H}), 1749,1716(\mathrm{C}=\mathrm{O}), 1608,1452\left(\mathrm{C}=\mathrm{C}_{\mathrm{Ar}}\right)$, $1257(\mathrm{C}-\mathrm{O}-\mathrm{C}), 1134,1035(\mathrm{C}-\mathrm{O}), 852\left(\mathrm{C}-\mathrm{H}_{\mathrm{Ar}}\right) ;{ }^{1} \mathrm{H} \mathrm{NMR}$ $\left(400 \mathrm{MHz}, \mathrm{DMSO}-d_{6}\right) \delta 7.45$ (ddd, $J 15.2,7.9,2.4 \mathrm{~Hz}, 1 \mathrm{H}$, H-3), 7.24 (d, J 1.5 Hz, 1H, H-7), 7.10-6.98 (m, 3H, H-4, H-5, H-11), 6.94 (d, J 8.0 Hz, 1H, H-10), 6.08 (d, J $15.2 \mathrm{~Hz}$, $3 \mathrm{H}, \mathrm{H}-2, \mathrm{H}-12), 4.73$ (s, 2H, H-13), 4.09 (t, 2H, H-15), 1.56 (m, 2H, H-16), 1.25 (m, 10H, H-17, H-18, H-19, H-20, $\mathrm{H}-21), 0.84$ (t, 3H, H-22); ${ }^{13} \mathrm{C}$ NMR (101 MHz, DMSO- $d_{6}$ ) $\delta 168.3$ (C-14), 166.1 (C-1), 148.8 (C-9), 148.5 (C-8), 146.8 (C-3), 141.7 (C-5), 130.8 (C-6), 124.9 (C-4), 123.9 (C-11), 118.9 (C-2), 109.0 (C-10), 106.2 (C-7), 101.9 (C-12), 65.1 (C-15), 61.0 (C-13), 31.6 (C-16), 29.1 (C-17), 29.0 (C-18), 28.5 (C-19), 25.7 (C-20), 22.5 (C-21), 14.3 (C-22).

\section{2-Decyloxy-2-oxoethyl-piperate (6k)}

Pale yellow solid; MW $416.51 \mathrm{~g} \mathrm{~mol}^{-1}$; yield: 64\%; mp 73-74 ${ }^{\circ} \mathrm{C}$; IR (ATR) $v / \mathrm{cm}^{-1} 3018\left(\mathrm{C}-\mathrm{H}_{\mathrm{Ar}}\right), 2918$, $2846(\mathrm{C}-\mathrm{H}), 1739,1722(\mathrm{C}=\mathrm{O}), 1602,1450\left(\mathrm{C}=\mathrm{C}_{\mathrm{Ar}}\right)$, $1253(\mathrm{C}-\mathrm{O}-\mathrm{C}), 1201,1085,1031(\mathrm{C}-\mathrm{O}), 852\left(\mathrm{C}-\mathrm{H}_{\mathrm{Ar}}\right)$; ${ }^{1} \mathrm{H}$ NMR (400 MHz, DMSO- $d_{6}$ ) $\delta 7.45$ (ddd, $J$ 15.2, 7.8, $2.5 \mathrm{~Hz}, 1 \mathrm{H}, \mathrm{H}-3), 7.25$ (d, J 1.5 Hz, 1H, H-7), 7.10-6.98 (m, 3H, H-4, H-5, H-11), 6.94 (d, J 8.0 Hz, 1H, H-10), 6.08 (d, J $15.6 \mathrm{~Hz}, 3 \mathrm{H}, \mathrm{H}-2, \mathrm{H}-12), 4.73$ (s, 2H, H-13), 4.09 (t, 2H, H-15), 1.66-1.50 (m, 2H, H-16), 1.22 (m, 14H, H-17, H-18, H-19, H-20, H-21, H-22, H-23), 0.84 (t, 4H, H-24); ${ }^{13} \mathrm{C}$ NMR (101 MHz, DMSO- $\left.d_{6}\right) \delta 168.3$ (C-14), 166.1 (C-1), 148.8 (C-9), 148.4 (C-8), 146.8 (C-3), 141.7 (C-5), 130.8 (C-6), 124.9 (C-4), 123.9 (C-11), 118.9 (C-2), 109.0 (C-10), 106.2 (C-7), 101.9 (C-12), 65.1 (C-15), 61.0 (C-13), 31.7 (C-16), 29.4 (C-17), 29.4 (C-18), 29.2 (C-19), 29.1 (C-20), 28.5 (C-21), 25.7 (C-22), 22.5 (C-23), 14.3 (C-24).

\section{2-Dodecyloxy-2-oxoethyl-piperate (6I)}

Pale yellow solid; MW $444.57 \mathrm{~g} \mathrm{~mol}^{-1}$; yield: $63 \%$; 
mp 65-66 ${ }^{\circ} \mathrm{C}$; IR (ATR) $v / \mathrm{cm}^{-1} 3024\left(\mathrm{C}-\mathrm{H}_{\mathrm{Ar}}\right), 2953$, 2920, $2852(\mathrm{C}-\mathrm{H}), 1749,1712(\mathrm{C}=\mathrm{O}), 1606,1446\left(\mathrm{C}=\mathrm{C}_{\mathrm{Ar}}\right)$, $1251(\mathrm{C}-\mathrm{O}-\mathrm{C}), 1134,1035(\mathrm{C}-\mathrm{O}), 850\left(\mathrm{C}-\mathrm{H}_{\mathrm{Ar}}\right) ;{ }^{1} \mathrm{H}$ NMR $\left(400 \mathrm{MHz}, \mathrm{DMSO}-d_{6}\right) \delta 7.44$ (ddd, $J 15.2,7.7,2.6 \mathrm{~Hz}, 1 \mathrm{H}$, H-3), 7.24 (d, J 1.5 Hz, 1H, H-7), 7.09-6.98 (m, 3H, H-4, H-5, H-11), 6.93 (d, J 8.0 Hz, 1H, H-10), 6.08 (d, J $15.4 \mathrm{~Hz}$, $3 \mathrm{H}, \mathrm{H}-2, \mathrm{H}-12), 4.73$ (s, 2H, H-13), 4.09 (t, 2H, H-15), 1.67-1.48 (m, 2H, H-16), 1.41-1.13 (m, 18H, H-17, H-18, H-19, H-20, H-21, H-22, H-23, H-24, H-25), 0.84 (t, 3H, $\mathrm{H}-26) ;{ }^{13} \mathrm{C}$ NMR (101 MHz, DMSO- $\left.d_{6}\right) \delta 168.3$ (C-14), 166.1 (C-1), 148.8 (C-9), 148.4 (C-8), 146.8 (C-3), 141.7 (C-5), 130.8 (C-6), 124.9 (C-4), 123.9 (C-11), 118.9 (C-2), 108.9 (C-10), 106.2 (C-7), 101.9 (C-12), 65.0 (C-15), 61.0 (C-13), 31.7 (C-16), 29.5 (C-17), 29.5 (C-18), 29.4 (C-19, C-20), 29.2 (C-21), 29.1 (C-22), 28.5 (C-23), 25.7 (C-24), 22.5 (C-25), 14.3 (C-26).

\section{In silico study}

The parameters of Lipinski's rule of five: lipophilicity $(\operatorname{cog} \mathrm{P})$, molecular weight $(\mathrm{MW})$, hydrogen bond acceptors (HBA), hydrogen bonding donors (HBD) and topological polar surface area (TPSA) were calculated using the online program Molinspiration. ${ }^{18}$ The aqueous solubility (LogS), drug-likeness and drug-score parameters were calculated using the OSIRIS Property Explorer software. ${ }^{19}$ The percentage of theoretical absorption (ABS) of the compounds was calculated using the equation: $\operatorname{ABS}(\%)=109-0.345 \operatorname{TPSA}^{20}$

\section{Antimicrobial activity}

\section{Culture media}

The culture media used for maintenance of bacterial and fungal strains were brain heart infusion (BHI) and Sabouraud dextrose agar (SDA) (acquired from Difco Laboratories Ltd., Detroit, USA), respectively. For the pharmacological activity assays, BHI liquid nutrient medium for bacteria and Roswell Park Memorial Institute (RPMI) 1640 with L-glutamine and without bicarbonate for fungi (Difco Laboratories Ltd., Detroit, USA, and INLAB, São Paulo, Brazil) were used. The culture media were prepared according to the manufacturers' instructions.

\section{Microorganisms}

For the antimicrobial activity assays of the compounds, the following strains were used: Staphylococcus aureus (American Type Culture Collection (ATCC)-25923), Pseudomonas aeruginosa (ATCC-25853), Candida albicans (ATCC-60193 and LM-92), Candidatropicalis (ATCC-13803 and LM-18), Aspergillus fumigatus (ATCC-40640 and IPP-210), Aspergillus flavus (LM-714) and Aspergillus niger (LM-108). The microorganisms belong to the collection of the Mycology Laboratory, Department of Pharmaceutical Sciences (DCF), Center of Health Sciences (CCS) of the Federal University of Paraíba (UFPB). The strains were stored in BHI (bacteria) and in SDA (fungi) at $4{ }^{\circ} \mathrm{C}$. Samples of bacterial and fungal (yeasts) colonies incubated at $35 \pm 2{ }^{\circ} \mathrm{C}$ for $24-48 \mathrm{~h}$ and filamentous fungi colonies incubated at $28 \pm 2{ }^{\circ} \mathrm{C}$ for 7-14 days were used for the assays. To prepare the inoculum, the colonies obtained from cultures of bacterial strains in BHI medium and fungi in SDA medium were suspended in sterile saline solution $(0.9 \%$ $\mathrm{NaCl}$ ) according to the $0.5 \mathrm{McFarland}$ standard, adjusted using a spectrophotometer (Leitz-Photometer 340-800) to $90 \% \mathrm{~T}(530 \mathrm{~nm})$, corresponding to approximately $10^{6}$ colony forming unit (CFU) $\mathrm{mL}^{-1}$ for fungi and $10^{8} \mathrm{CFU} \mathrm{mL} \mathrm{m}^{-1}$ for bacteria. ${ }^{21,22}$

\section{Determination of minimum inhibitory concentration (MIC)}

The determination of the MIC of the products against the bacterial and fungal strains was performed using the broth microdilution technique with cell-culture microplates (TPP, Trasadingen, Switzerland, Europe) with 96 roundbottom wells. Initially, $100 \mu \mathrm{L}$ of RPMI/BHI broth were distributed in the wells of the microdilution plates. Next, $100 \mu \mathrm{L}$ of the substances were dispensed in the wells of the first row of the plate, and 2-fold serial dilution was performed, giving concentrations of 1024 up to $64 \mu \mathrm{g} \mathrm{mL}{ }^{-1}$. Finally, $10 \mu \mathrm{L}$ of the bacterial and fungal suspensions were added to the wells. In parallel, the controls were performed: microorganisms (BHI + bacteria and RPMI + fungi) and culture medium (RPMI/BHI), to assure the strains viability and sterility of the medium, respectively; and negative control with antimicrobials: gentamicin $\left(100 \mu \mathrm{g} \mathrm{mL} \mathrm{m}^{-1}\right)$ for bacteria and amphotericin B $\left(1 \mu \mathrm{g} \mathrm{mL}^{-1}\right)$ for fungi. The prepared plates were aseptically closed and incubated at $35 \pm 2{ }^{\circ} \mathrm{C}$ for $24-48 \mathrm{~h}$ for bacteria and yeasts at $28 \pm 2{ }^{\circ} \mathrm{C}$ for 7-14 days for filamentous fungi. MIC was defined as the lowest concentration capable of visually inhibiting complete microbial growth. The results were expressed as the mean. In the biological assay with bacteria, after $24 \mathrm{~h}$ of incubation, $20 \mu \mathrm{L}$ of $0.01 \%$ resazurin dye solution (INLAB) were added; this dye is recognized as a colorimetric redox indicator. ${ }^{23}$ A change in dye color (blue to red) indicated microbial growth; and, if the color remained blue, there was no microbial growth. The MIC for each product was defined as the lowest concentration capable of visually inhibiting microbial growth and/or verified by no change in color of the indicator dye. 


\section{Results and Discussion}

\section{Chemistry}

The synthesis of the diesters derived from piperine (6a-6l) was performed in five stages, which are described in Scheme 1.

Initially, piperine (1), extracted from black pepper (Piper nigrum L.), was subjected to basic hydrolysis $(i)$ followed by acidification (ii) to obtain piperic acid (2). ${ }^{16} \mathrm{We}$ decided to use a salt of piperic acid (3), as a nucleophile, to easily remove the reaction medium by the addition of water, which was obtained by the neutralization reaction of piperic acid with an ethanolic $\mathrm{KOH}$ solution (1:1) (iii). The alkyl 2-chloroacetate intermediates (5a-5l) were obtained via two methods: (iv) Fisher esterification, ${ }^{24}$ readily and suitable for small liquid alcohols molecules, where the excess alcohol can be removed by rotary evaporation, and $(v)$ esterification via acid chloride, ${ }^{25}$ an efficient method for larger chain alcohols. The final compounds were obtained through the bimolecular nucleophilic substitution reaction $\left(S_{N} 2\right)$ between alkyl 2-chloroacetates $(\mathbf{5 a}-5 \mathbf{l})$ and the piperate (3) in slight excess to ensure that there was no residual chloroester, where this excess salt could be easily removed by the addition of water. Thus, it was possible to obtain 12 novel piperine diester derivatives (6a-6l).

\section{Characterization of final products}

The structures of the piperine derivatives were confirmed using IR and ${ }^{1} \mathrm{H}$ and ${ }^{13} \mathrm{C}$ NMR, including the 2D techniques ${ }^{1} \mathrm{H},{ }^{1} \mathrm{H}-\mathrm{COSY}$ and ${ }^{1} \mathrm{H},{ }^{13} \mathrm{C}$-HSQC and HMBC. In the IR spectrum of the piperine derivatives (6a-6l), the presence of the aromatic and aliphatic groups was evidenced by the axial deformation of the $\mathrm{C}-\mathrm{H}$ bonds in the region from 3080 to $2850 \mathrm{~cm}^{-1}$. Axial deformation of the $\mathrm{C}=\mathrm{C}$ connections between 1612 and $1450 \mathrm{~cm}^{-1}$ was also observed in the spectra. The absorptions of the carbonyl groups $(\mathrm{C}=\mathrm{O})$ appeared between 1761 and $1697 \mathrm{~cm}^{-1}$. The axial deformation bands of the $\mathrm{C}-\mathrm{O}$ linkage of the esters appeared around 1300 and $1100 \mathrm{~cm}^{-1}$, and in the region of $1250 \mathrm{~cm}^{-1}$ there was a band referring to the $(\mathrm{C}-\mathrm{O}-\mathrm{C})$ portion of the methylenedioxy ring, an important signal in identifying compounds derived from piperine.

In the NMR spectrum of compound 6c, signals were observed in the aromatic and olefinic regions at $\delta_{\mathrm{H}}$ 7.52-6.00, referring to the seven hydrogens. At $\delta_{\mathrm{H}} 5.98$, there was a singlet for two hydrogens (H-12), referring to the hydrogens of the methylenedioxy ring. The 2D studies $\left({ }^{1} \mathrm{H},{ }^{1} \mathrm{H}-\mathrm{COSY}\right)$ showed the following correlations: the triplet $\left[\delta_{\mathrm{H}} 4.13(\mathrm{t}, J 6.7 \mathrm{~Hz})\right]$ and the multiplet $\left[\delta_{\mathrm{H}} 1.67(\mathrm{~m})\right]$ for the hydrogens of $\mathrm{H}-15$ with $\mathrm{H}-16$; between the multiplet $\mathrm{H}-16\left[\delta_{\mathrm{H}} 1.67(\mathrm{~m})\right]$ and triplet $\mathrm{H}-15\left[\delta_{\mathrm{H}} 4.14(\mathrm{t}, J 6.7 \mathrm{~Hz})\right]$ and the multiplet $\mathrm{H}-16\left[\delta_{\mathrm{H}} 1.67(\mathrm{~m})\right]$ with the triplet of $\mathrm{H}-17$ $\left[\delta_{\mathrm{H}} 0.94(\mathrm{t}, J 7.4 \mathrm{~Hz})\right]$; and the multiplet $\left[\delta_{\mathrm{H}} 1.67(\mathrm{~m})\right]$ and triplet $\left[\delta_{\mathrm{H}} 0.94(\mathrm{t}, J 7.4 \mathrm{~Hz})\right]$ for the hydrogens of $\mathrm{H}-16$ with $\mathrm{H}-17$. The $2 \mathrm{D}$ direct correlation spectrum $\left({ }^{1} \mathrm{H},{ }^{13} \mathrm{C}-\mathrm{HSQC}\right)$ showed correlations between the signal at $\delta_{\mathrm{H}} 4.69$, referring to the methylene hydrogens $(\mathrm{H}-13)$, and the carbon signal at $\delta_{\mathrm{C}} 60.8(\mathrm{C}-13)$, and between the signal at $\delta_{\mathrm{H}} 5.98$, referring to the hydrogens $(\mathrm{H}-12)$, and the carbon signal at $\delta_{\mathrm{C}} 101.5(\mathrm{C}-12)$.
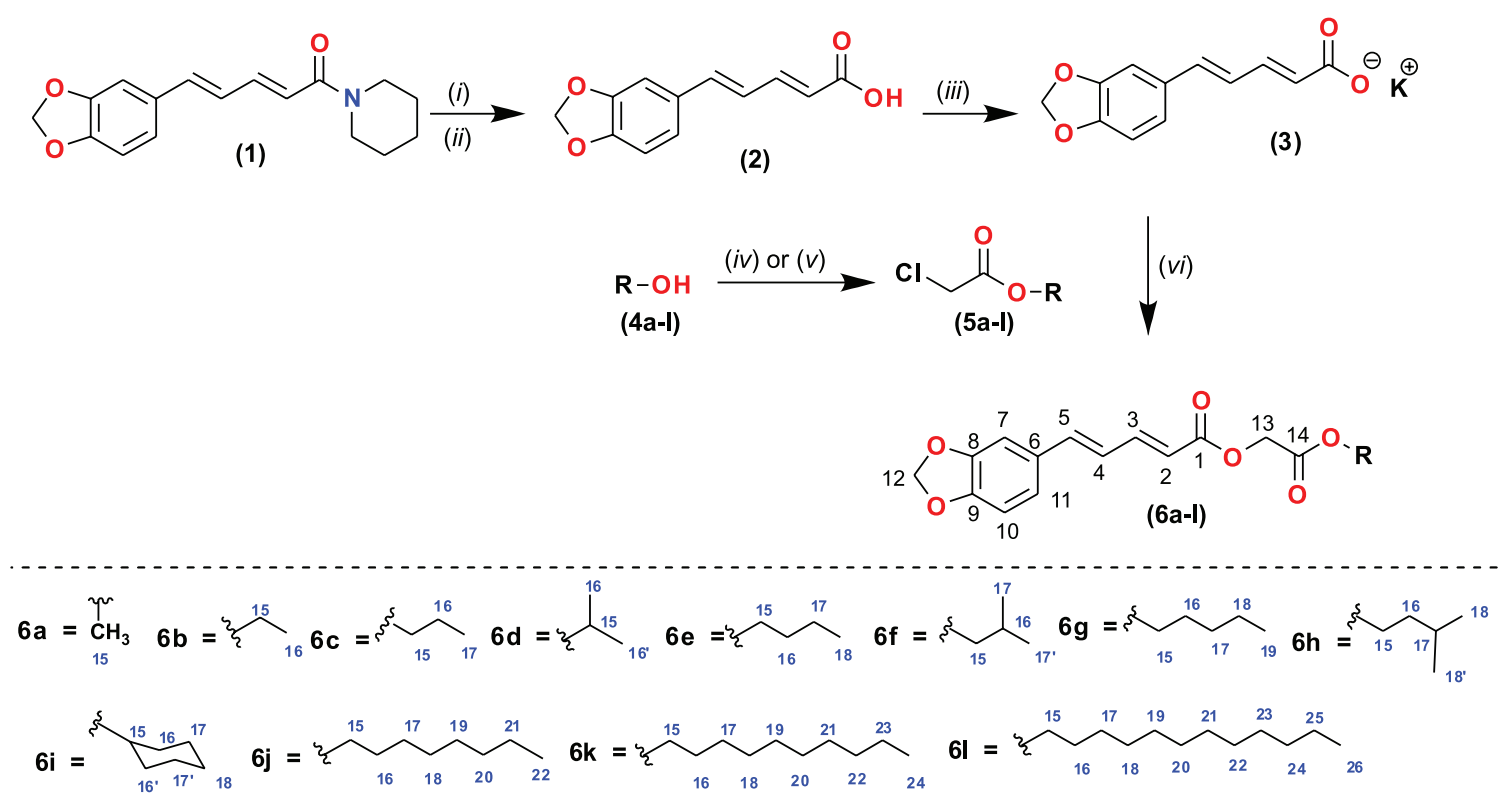

Scheme 1. Synthetic route for the target molecules. Reagents and conditions: (i) $\mathrm{KOH} 20 \%$, EtOH, reflux, $20 \mathrm{~h}$; (ii) $\mathrm{HCl}(94 \%)$; (iii) $\mathrm{KOH}$, EtOH, room temperature, $1 \mathrm{~h}, 93 \%$; (iv) for 4a-4h; $\mathrm{ClCH}_{2} \mathrm{COOH}, \mathrm{H}_{2} \mathrm{SO}_{4(\mathrm{Cat})}, 6 \mathrm{~h},(75-93 \%)$; (v) for $4 \mathbf{i}-4 \mathbf{4} ; \mathrm{ClCH}_{2} \mathrm{COCl}, \mathrm{Et}_{3} \mathrm{~N}, \mathrm{DCM}, 20 \mathrm{~h}, 63-67 \%$; (vi) DMF, KI, $100{ }^{\circ} \mathrm{C}, 24 \mathrm{~h}, 55-84 \%$. 
Concerning the ${ }^{1} \mathrm{H}$ NMR analysis of compound $\mathbf{6 c}$, all other diesters showed a characteristic singlet for methylene hydrogens, referring to the methylenedioxy ring (H-12) with a shift at $\delta_{\mathrm{H}}$ 6.07-5.98 and a singlet of methylene hydrogens $(\mathrm{H}-13)$ at $\delta_{\mathrm{H}} 4.76-4.69$.

In the ${ }^{13} \mathrm{C}$ NMR spectrum, all piperine derivatives (6a-6l) showed two characteristic signals attributed to C-1 and C-14 carbonyls varying in the range of $\delta_{\mathrm{C}}$ 168.8-166.1. Analyzing the 2D HMBC spectrum of compound $\mathbf{6 c}$, it was possible to unequivocally attribute the chemical shifts of both carbonyl moieties present in the compound from the correlations between ${ }^{13} \mathrm{C}$ and ${ }^{1} \mathrm{H}$ separated by 2 and 3 bonds. The $\mathrm{H}-15$ methylene hydrogens at $\delta_{\mathrm{H}} 4.13$ couples with the carbon C-16 at $\delta_{\mathrm{C}} 22.0$, with carbon C-17 at $\delta_{\mathrm{C}} 10.3$ and carbonyl C-14 at $\delta_{\mathrm{C}} 168.1$. Olefinic hydrogen $\mathrm{H}-2$ at $\delta_{\mathrm{H}} 6.02$ correlated with carbonyl C-1 at $\delta_{\mathrm{C}} 166.4$.

Based on compound $\mathbf{6 c}$ analyses, the C-1 and C-14 carbons of the 6a-6l compounds were recorded in the range of $\delta_{\mathrm{C}} 166.4-166.1$ and $\delta_{\mathrm{C}} 168.8-167.7$, respectively. The compounds showed two more characteristic signals of methylene carbons referring to $\mathrm{C}-12$ and $\mathrm{C}-13$, in the range of $\delta_{\mathrm{C}}$ 101.9-101.4 and $\delta_{\mathrm{C}} 61.2-60.7$, respectively. In all compounds, the signals attributed to the aromatic carbons were in the range of $\delta_{\mathrm{C}}$ 148.8-105.9.

In the ${ }^{13} \mathrm{CNMR}$ spectrum for compound $\mathbf{6 a}$, a characteristic signal is observed for the methyl group in the aliphatic region at $\delta_{\mathrm{C}}$ 52.3. For compound $\mathbf{6 b}$ it shows two signals of the ethyl group, at $\delta_{\mathrm{C}} 61.0$ and 14.4. For compound 6d, two characteristic signals of the isopropyl group appear in $\delta_{\mathrm{C}} 68.9$ and 21.9. For compound $\mathbf{6 e}$, four signals were found for the butyl group, a signal at $\delta_{\mathrm{C}} 64.8$ and three in the $\delta_{\mathrm{C}}$ range of 30.5-13.9. For the $\mathbf{6}$ compound, the three signals for isobutyl group appear in $\delta_{\mathrm{C}} 70.7,27.7$ and 19.1. For the $\mathbf{6 g}$ compound, it shows five signals that characterizes the pentyl group, being a chemical displacement at $\delta_{\mathrm{C}} 65.1$ and four signals in the $\delta_{\mathrm{C}}$ range of 28.1-14.2. For compound $\mathbf{6 h}$, four characteristic signals of the isopentyl group are observed, a signal around $\delta_{\mathrm{C}} 63.6$ and three signals in $\delta_{\mathrm{C}}$ range of 37.1-22.6. For compound $\mathbf{6 i}$, four signals were observed, one in $\delta_{\mathrm{C}} 73.3$ and three signals in the range of $\delta_{\mathrm{C}} 31.5-23.3$, regarding the cyclohexyl group. For compound $\mathbf{6 j}$, eight signals belonging to the octyl group were recorded, one in $\delta_{\mathrm{C}} 65.1$ and the other seven signals are in the range of $\delta_{\mathrm{C}} 31.6-14.3$. For compound $\mathbf{6 k}$, ten chemical shift signals were attributed to the decyl group, one in $\delta_{\mathrm{C}} 65.1$ and nine in the range of $\delta_{\mathrm{C}} 31.7-14.3$. Compound $\mathbf{6} \mathbf{1}$ showed eleven signals representing the dodecyl group, with ten chemical shift signals in the range of $\delta_{\mathrm{C}} 31.7-14.3$ and one around $\delta_{\mathrm{C}}$ 65.0.

\section{In silico study}

In the present study, the theoretical potential of the synthesized compounds was investigated by the in silico approach of the Lipinski's rule of five, ${ }^{26-28}$ where they identified that, for good absorption and permeation, the drug must comply with at least three of the following four criteria: $\mathrm{HBA} \leq 10 ; \mathrm{HBD} \leq 5 ; \mathrm{MW} \leq 500 ; \operatorname{clog} \mathrm{P} \leq 5$. The parameters as percentage of theoretical absorption (ABS), aqueous solubility ( $\operatorname{LogS})$, drug-likeness and drug-score were also calculated. The results of the in silico study for the diesters derived from piperine are presented in Table 1.

According to the results of the in silico study presented in Table 1, all compounds satisfy the Lipinski's rule with no violation, with the exception of compounds $\mathbf{6 j}, \mathbf{6 k}$ and

Table 1. In silico study of piperine derivatives $(\mathbf{6 a - 6 1 )}$

\begin{tabular}{|c|c|c|c|c|c|c|c|c|c|c|}
\hline \multirow{2}{*}{ Compound } & \multicolumn{5}{|c|}{ Lipinski's parameter } & \multirow{2}{*}{ TPSA / $\AA^{2}$} & \multirow{2}{*}{ ABS $/ \%$} & \multirow{2}{*}{$\log S$} & \multirow{2}{*}{ Drug-likeness } & \multirow{2}{*}{ Drug score } \\
\hline & HBA & HBD & MW & $\operatorname{clog} \mathrm{P}$ & nViol & & & & & \\
\hline $6 a$ & 6 & 0 & 290.27 & 2.23 & 0 & 71.06 & 84.484 & -3.05 & -2.82 & 0.28 \\
\hline $6 \mathbf{b}$ & 6 & 0 & 304.30 & 2.63 & 0 & 71.06 & 84.484 & -3.35 & -4.39 & 0.26 \\
\hline $6 c$ & 6 & 0 & 318.32 & 3.09 & 0 & 71.06 & 84.484 & -3.62 & -0.82 & 0.31 \\
\hline 6d & 6 & 0 & 318.32 & 2.99 & 0 & 71.06 & 84.484 & -3.73 & -3.16 & 0.25 \\
\hline $6 e$ & 6 & 0 & 332.35 & 3.54 & 0 & 71.06 & 84.484 & -3.89 & -5.58 & 0.13 \\
\hline 6f & 6 & 0 & 332.35 & 3.31 & 0 & 71.06 & 84.484 & -3.78 & -0.72 & 0.18 \\
\hline $6 \mathrm{~g}$ & 6 & 0 & 346.38 & 4.00 & 0 & 71.06 & 84.484 & -4.16 & -9.82 & 0.13 \\
\hline $6 \mathrm{~h}$ & 6 & 0 & 346.38 & 3.76 & 0 & 71.06 & 84.484 & -4.05 & -0.31 & 0.24 \\
\hline $6 i$ & 6 & 0 & 358.39 & 3.78 & 0 & 71.06 & 84.484 & -4.63 & -5.40 & 0.20 \\
\hline $6 \mathbf{j}$ & 6 & 0 & 388.46 & 5.36 & 1 & 71.06 & 84.484 & -4.97 & -22.25 & 0.14 \\
\hline $6 \mathrm{k}$ & 6 & 0 & 416.51 & 6.27 & 1 & 71.06 & 84.484 & -5.51 & -22.25 & 0.11 \\
\hline 61 & 6 & 0 & 444.57 & 7.18 & 1 & 71.06 & 84.484 & -6.05 & -22.25 & 0.09 \\
\hline
\end{tabular}

HBA: hydrogen bond acceptor; HBD: hydrogen bond donor; MW: molecular weight; clogP: octanol/water partition coefficient based on Molinspiration; nViol: number of violations; TPSA: topological surface area; ABS: absorption percentage; LogS: solubility. 
61, which violated the lipophilicity parameter $\operatorname{cog} \mathrm{P}>5$, suggesting that the great majority of the compounds should demonstrate good oral bioavailability. In the TPSA parameter, which indicates that molecules with TPSA $\leq 140 \AA^{2}$ have better oral bioavailability and a higher permeation rate, ${ }^{27}$ the results showed that the synthesized compounds showed TPSA values equal to $71.06 \AA^{2}$, which indicates good permeability through the cell membrane, reflecting a high percentage of absorption (84.48\%). Most commercial medications have $\operatorname{LogS}\left(\mathrm{mol} \mathrm{L}^{-1}\right)>-4.00$ (OSIRIS Property Explorer), ${ }^{19}$ while in the results presented, we found that only compounds 6a-6f had $\operatorname{LogS}>-4.00$. The compounds displayed values of druglikeness in the range of -22.25 to -0.31 , with $\mathbf{6 h}$ having the highest value. The drug-score values combine the parameters of lipophilicity, aqueous solubility, molecular weight, similarity of the drug and risk of toxicity, and their values are often used to predict the potential of the test compounds to be new medications. The drug-score values of the diesters derived from piperine ranged between 0.09 and 0.31 , with the lowest value for $\mathbf{6} \mathbf{l}$ and the highest value for $\mathbf{6 c}$.

\section{Antimicrobial study}

The in vitro antimicrobial activity of compounds 6a-6l was evaluated by the microdilution method on bacterial strains (Staphylococcus aureus ATCC-25923; Pseudomonas aeruginosa ATCC-25853), yeasts (Candida albicans ATCC-60193 and LM-92; C. tropicalis
ATCC-13803 and LM-18), and filamentous fungi (Aspergillus fumigatus ATCC-40640 and IPP-210; A. flavus LM-714; A. niger LM-108). The products were weighed and dissolved in 5\% DMSO-2\% Tween 80 completing the final volume with sterile distilled water, obtaining an emulsion of the products at the initial concentration of $1024 \mu \mathrm{g} \mathrm{mL}{ }^{-1} .29-31$ The results of the antimicrobial activity of compounds 6a-6l are shown in Table 2.

As shown in Table 2, no substance was able to inhibit microbial growth of the bacterial strains. Substances $\mathbf{6 j}$, $\mathbf{6 k}$ and $\mathbf{6} \mathbf{l}$ were inactive for all microorganisms tested. Substances 6a-6i were active against all Candida yeasts, displaying an MIC of 1024-256 $\mu \mathrm{g} \mathrm{mL} \mathrm{mL}^{-1}$. Compounds 6a-6e had an MIC of $256 \mu \mathrm{g} \mathrm{mL}^{-1}$ against the filamentous fungus A. niger LM-108. Of the test substances, only $\mathbf{6 e}$ was active against A. flavus LM-714 with MIC of $1024 \mu \mathrm{g} \mathrm{mL} \mathrm{m}^{-1}$. Compound $6 \mathrm{~g}$ was effective with an MIC of $1024 \mu \mathrm{g} \mathrm{mL}$ against $40 \%$ of the microorganisms used, and this percentage was composed only of yeasts. For $50 \%$ of the microbial strains used, substance $\mathbf{6 d}$ showed an MIC of $512 \mu \mathrm{g} \mathrm{mL} \mathrm{m}^{-1}$; product $\mathbf{6 c}$ had an MIC of $256 \mu \mathrm{g} \mathrm{mL} \mathrm{L}^{-1}$, while $6 \mathbf{f}$ and $6 \mathbf{i}$ had an MIC of $1024 \mu \mathrm{g} \mathrm{mL} \mathrm{L}^{-1}$. 6a, $6 \mathbf{b}$ and $6 \mathbf{e}$ were active against $70 \%$ of the microorganisms used, with an MIC of $1024 \mu \mathrm{gL}^{-1}$ for compound $6 \mathbf{e}$ and an MIC of $512 \mu \mathrm{g} \mathrm{mL} \mathrm{L}^{-1}$ for $\mathbf{6 a}$ and $\mathbf{6 b}$.

The variation in antimicrobial capacity of the final compounds 6a-61 may probably be related to differences in lipophilicity and solubility. The lack of activity displayed

Table 2. Minimum inhibitory concentration of the piperine-derived diesters $\mathbf{6 a - 6 1}$ against bacterial and fungal strains

\begin{tabular}{|c|c|c|c|c|c|c|c|c|c|c|}
\hline \multirow{3}{*}{ Compound } & \multicolumn{10}{|c|}{$\mathrm{MIC} /\left(\mu \mathrm{g} \mathrm{mL} L^{-1}\right)$} \\
\hline & \multicolumn{2}{|c|}{ Bacteria } & \multicolumn{4}{|c|}{ Yeast } & \multicolumn{4}{|c|}{ Filamentous fungi } \\
\hline & $\begin{array}{c}\text { S. aureus } \\
\text { ATCC-25923 }\end{array}$ & $\begin{array}{l}\text { P. aeruginosa } \\
\text { ATCC- } 25853\end{array}$ & $\begin{array}{c}\text { C. albicans } \\
\text { ATCC-60193 }\end{array}$ & $\begin{array}{c}\text { C. albicans } \\
\text { LM-92 }\end{array}$ & $\begin{array}{c}\text { C. tropicalis } \\
\text { ATCC-13803 }\end{array}$ & $\begin{array}{l}\text { C. tropicalis } \\
\text { LM-18 }\end{array}$ & $\begin{array}{l}\text { A. flavus } \\
\text { LM-714 }\end{array}$ & $\begin{array}{l}\text { A. niger } \\
\text { LM-108 }\end{array}$ & $\begin{array}{l}\text { A. fumigatus } \\
\text { ATCC-40640 }\end{array}$ & $\begin{array}{l}\text { A. fumigatus } \\
\text { IPP-210 }\end{array}$ \\
\hline $6 a$ & + & + & 256 & 1024 & 1024 & 1024 & + & 256 & 256 & 256 \\
\hline $6 b$ & + & + & 256 & 1024 & 1024 & 1024 & + & 256 & 256 & 256 \\
\hline $6 c$ & + & + & 1024 & 256 & 1024 & 256 & + & 256 & + & + \\
\hline 6d & + & + & 1024 & 1024 & 512 & 512 & + & 256 & + & + \\
\hline $6 e$ & + & + & 1024 & 1024 & 1024 & 1024 & 1024 & 256 & + & 1024 \\
\hline $6 f$ & + & + & 1024 & 1024 & 1024 & 1024 & + & + & + & 512 \\
\hline $6 \mathrm{~g}$ & + & + & 1024 & 512 & 1024 & 1024 & + & + & + & + \\
\hline $6 h$ & + & + & 256 & a & 1024 & 1024 & + & + & 256 & + \\
\hline $6 \mathbf{i}$ & + & + & 1024 & 1024 & 1024 & 1024 & + & + & + & 1024 \\
\hline $6 \mathbf{j}$ & + & + & + & + & + & + & + & + & + & + \\
\hline $6 \mathbf{k}$ & + & + & + & + & + & + & + & + & + & + \\
\hline 61 & + & + & + & + & + & + & + & + & + & + \\
\hline Culture media & - & - & - & - & - & - & - & - & - & - \\
\hline Microorganism & + & + & + & + & + & + & + & + & + & + \\
\hline Amphotericin B & $\mathrm{a}$ & $\mathrm{a}$ & - & - & - & - & - & - & - & - \\
\hline Gentamicin & - & - & a & a & a & $\mathrm{a}$ & a & $\mathrm{a}$ & a & $\mathrm{a}$ \\
\hline
\end{tabular}

aNot tested. MIC: minimum inhibitory concentration; ATCC: American Type Culture Collection; +: presence of microbial growth; -: no microbial growth. 
by compounds $\mathbf{6 j}, \mathbf{6 k}$ and $\mathbf{6} \mathbf{l}$ may be due to their high lipophilicity values. As seen in the in silico study, only these diesters showed lipophilicity values ( $\operatorname{cog} \log )$ higher than 5 . If a drug is very lipophilic, it can very strongly bind to plasma proteins, being unable to reach the intracellular space, and thus, the plasma concentration of free drug decreases and drug's potency/efficacy may be reduced. ${ }^{32}$

\section{Conclusions}

In this work, twelve new diesters derived from piperine were synthesized and their structures were confirmed by IR, ${ }^{1} \mathrm{H}$ and ${ }^{13} \mathrm{C}$ NMR, COSY, HMBC and HSQC. The in silico study showed that compounds $\mathbf{6 a - 6 i}$ did not violate the Lipinski's rule of five, so they should have good oral bioavailability. The in vitro antimicrobial activity assay showed that compounds $6 \mathbf{6}, \mathbf{6 b}$ and $\mathbf{6 e}$ were active against $70 \%$ of the strains used with an MIC of 1024-256 $\mu \mathrm{g} \mathrm{mL}^{-1}$, while compounds $\mathbf{6 j}, \mathbf{6 k}$ and $\mathbf{6} \mathbf{l}$ were inactive against all strains at the concentrations used. The antimicrobial activity of these compounds may be related to lipophilic factors and the hydrophobic character of these molecules. To fully understand the relationship between the physicochemical properties and the biological activity observed in the in vitro study, further structure-activity relationship studies are warranted.

\section{Supplementary Information}

Supplementary information is available free of charge at http://jbcs.sbq.org.br as PDF file.

\section{Acknowledgments}

This work was supported by the Brazilian agencies, CNPq, CAPES and FAPESQ-PB. Dr A. Leyva (USA) provided English editing of the article.

\section{Author Contributions}

Emmely O. Trindade and Petrônio F. de Athayde-Filho conceived and designed the study; Emmely O. Trindade, Maria Cláudia R. Brandão, Helivaldo D. S. Souza and Bruno F. Lira performed the experiments; Emmely O. Trindade, Helivaldo D. S. Souza, Maria Cláudia R. Brandão carried out the in silico study and analyzed the data; Hermes D. Neto and Edeltrudes O. Lima performed the antimicrobial study; and Emmely O. Trindade, Helivaldo D. S. Souza, Petrônio F. de Athayde-Filho and José M. Barbosa-Filho wrote the paper.

\section{References}

1. Ventola, C. L.; Pharm. Ther. 2015, 40, 277.

2. Almeida, F.; Rodrigues, M. L.; Coelho, C.; Front. Microbiol. 2019, 10, 214.

3. Nascimento, G. G. F.; Locatelli, J.; Freitas, P. C.; Silva, G. L.; Braz. J. Microbiol. 2000, 31, 247.

4. Sangwan, P. L.; Koul, J. L.; Koul, S.; Reddy, M. V.; Thota, N.; Khan, I. A.; Kumar, A.; Kalia, N. P.; Qazi, G. N.; Bioorg. Med. Chem. 2008, 16, 9847.

5. de Oliveira, C. S.; Lira, B. F.; Barbosa-Filho, J. M.; Lorenzo, J. G. F.; de Menezes, C. P.; dos Santos, J. M. C. G.; Lima, E. O.; de Athayde-Filho, P. F.; J. Braz. Chem. Soc. 2013, 24, 115.

6. Chinta, G.; Syed, S. B.; Coumar, M. S.; Periyasamy, L.; Curr. Bioact. Compd. 2015, 11, 156.

7. Majeed, M.; Prakash, L.; Int. Pepper News 2000, 25, 23.

8. Gupta, R. A.; Motiwala, M. N.; Dumore, N. G.; Danao, K. R.; Ganjare, A. B.; J. Ethnopharmacol. 2015, 164, 239.

9. Singh, V. K.; Singh, P.; Mishra, A.; Patel, A.; Yadav, K.; World J. Pharm. Res. 2014, 3, 2084.

10. Yasir, A.; Ishtiaq, S.; Jahangir, M.; Ajaib, M.; Salar, U.; Khan, K. M.; Med. Chem. 2018, 14, 269.

11. Amperayani, K. R.; Kumar, K. N.; Parimi, U. D.; Res. Chem. Intermed. 2018, 44, 3549.

12. Venugopal, D. V. R.; Med. Chem. 2014, 4, 606.

13. Kharbanda, C.; Alam, M. S.; Hamid, H.; Javed, K.; Bano, S.; Ali, Y.; Dhulap, A.; Alam, P.; Pasha, M. A. Q.; Chem. Biol. Drug Des. 2016, 88, 354.

14. Franklim, T. N.; Freire-de-Lima, L.; Chaves, O. A.; LaRocquede-Freitas, I. F.; da Silva-Trindade, J. D.; Netto-Ferreira, J. C.; Freire-de-Lima, C. G.; Decoté-Ricardo, D.; Previato, J. O.; Mendonça-Previato, L.; de Lima, M. E. F.; J. Braz. Chem. Soc. 2019, 30, 1378.

15. Venkatasamy, R.; Faas, L.; Young, A. R.; Raman, A.; Hider, R. C.; Bioorg. Med. Chem. 2004, 12, 1905.

16. Ikan, R.; Natural Products: A Laboratory Guide, $2^{\text {nd }}$ ed.; Academic Press: San Diego, USA, 1991.

17. Choochana, P.; Moungjaroen, J.; Jongkon, N.; Gritsanapan, W.; Tangyuenyongwatana, P.; Pharm. Biol. 2015, 53, 447.

18. http://www.molinspiration.com, accessed in March 2020.

19. https://www.organic-chemistry.org/prog/peo/, accessed in March 2020.

20. Zhao, Y. H.; Abraham, M. H.; Le, J.; Hersey, A.; Luscombe, C. N.; Beck, G.; Sherborne, B.; Cooper, I.; Pharm. Res. 2002, 19, 1446.

21. Holetz, F. B.; Homes, M. J.; Lee, C. C.; Steventon, G.; Mem. Inst. Oswaldo Cruz 2002, 97, 1027.

22. Sartoratto, A.; Machado, A. L. M.; Delarmelina, C.; Figueira, G. M.; Duarte, M. C. T.; Rehder, V. L. G.; Braz. J. Microbiol. 2004, 35, 275. 
23. Mann, C. M.; Markham, J. L.; J. Appl. Microbiol. 1998, 84, 538.

24. Gupta, R.; Kumar, P.; Narasimhan, B.; Arabian J. Chem. 2017, 10, S909.

25. Obłak, E.; Piecuch, A.; Krasowska, A.; Łuczyński, J.; Microbiol. Res. 2013, 168, 630.

26. Lipinski, C. A.; Lombardo, F.; Paul, D.; Feeney, P. J.; Adv. Drug Delivery Rev. 1997, 23, 3.

27. Lipinski, C. A.; Drug Discovery Today: Technol. 2004, 1, 337.

28. Lipinski, C. A.; Lombardo, F.; Dominy, B. W.; Feeney, P. J.; Adv. Drug Delivery Rev. 2001, 46, 3.

29. Cleland, R.; Squires, E. In Antibiotics in Laboratory Medicine; Lorian, V., ed.; Lippincott Williams \& Wilkins: Baltimore, 1991, p. 739.
30. Nascimento, P. F. C.; Nascimento, A. C.; Rodrigues, C. S.; Antoniolli, A. R.; Santos, M. P. O.; Júnior, A. M. B.; Trindade, R. C.; Rev. Bras. Farmacogn. 2007, 17, 108.

31. Pereira, F. O.; Mendes, J. M.; Lima, I. O.; Mota, K. S. L.; Oliveira, W. A.; Lima, E. O.; Pharm. Biol. 2015, 53, 228.

32. https://edisciplinas.usp.br/pluginfile.php/804016/mod_ resource/content/1/Propriedades $\% 20 \mathrm{f} \% \mathrm{C} 3 \% \mathrm{ADsico-}$ qu\%C3\%ADmicas.pdf, accessed in March 2020.

Submitted: November 12, 2019

Published online: March 24, 2020 